\title{
Nascedouro do Conselho Regional de Enfermagem de Santa Catarina (Década de 1970)*
}

Birth of the Regional Nursing Council of Santa Catarina (1970s)

Maria Lígia dos Reis Bellaguarda ${ }^{1}$, Maria Itayra Padilha ${ }^{2}$, André de Faria Pereira Neto ${ }^{3}$, Miriam Susskind Borenstein ${ }^{4}$

* Artigo extraído da Tese de Doutorado intitulada "Nexos e circunstâncias na história do Conselho Regional de Enfermagem em Santa Catarina (1975-1986)",

apresentada ao Programa de Pós Graduação da Universidade Federal de Santa Catarina em 23 de maio de 2013.

${ }^{1}$ Enfermeira, Doutora em Enfermagem. Professora da Faculdade Estácio de Sá Santa Catarina. São José, SC, Brasil. E-mail: bellaguardaml@gmail.com.

${ }^{2}$ Enfermeira, Doutora em Enfermagem. Professor Associado do Departamento de Enfermagem (NFR) da Universidade Federal de Santa Catarina (UFSC). Florianópolis,

SC, Brasil. E-mail: padilha@nfr.ufsc.br.

${ }^{3}$ Historiador, Doutor em Saúde Coletiva. Professor Titular da Fundação Oswaldo Cruz. Rio de Janeiro, RJ, Brasil. E-mail: apereira@fiocruz.br.

${ }^{4}$ Enfermeira, Doutora em Enfermagem. Professor Adjunto do NFR/UFSC. Florianópolis, SC, Brasil. E-mail: miriam@nfr.ufsc.br.

\section{RESUMO}

Estudo cujo objetivo foi analisar as circunstâncias de criação e instalação do Conselho Regional de Enfermagem em Santa Catarina. Pesquisa qualitativa, de cunho sócio-histórico, que utilizou análise de conteúdo para tratamento dos dados, emergindo duas categorias: O movimento para a criação do Conselho Regional de Enfermagem de Santa Catarina e Conjunturas de criação e instalação do Conselho Regional de Santa Catarina em 1975. A implantação do Conselho Profissional de Enfermagem seguiu as transformações sócio-históricas e políticas do trabalho em saúde no Brasil. As Lideranças da Associação Brasileira de Enfermagem atuaram garantindo certa autonomia profissional e poder sobre o seu trabalho, mesmo diante da fragilidade de entendimento da finalidade do órgão fiscalizador do fazer enfermagem pelos membros. O estudo possibilitou a compreensão dos nexos de influência do Conselho sobre a Enfermagem, institucionalizando a profissão com o registro de profissionais, regulamentando e disciplinando o exercício da profissão.

Descritores: Enfermagem; História; Conselhos de Especialidade Profissional.

\section{ABSTRACT}

The aim of this study was to analyze the circumstances of the creation and establishment of the Regional Nursing Council in the state of Santa Catarina. The research was qualitative and socio-historical, and used content analysis for data treatment. This resulted in two categories: the movement for the creation of the Regional Nursing Council of Santa Catarina and the circumstances surrounding the creation and establishment of the Regional Council of Santa Catarina in 1975. The creation of the Professional Nursing Council arose from the socio-historical and political transformations of health care work in Brazil. The leadership of the Brazilian Nursing Association ensured a certain professional autonomy and power over its work, even when confronted with the fragile understanding of the aims of an agency that supervised its members' nursing work. The study enabled the understanding of the nexuses of influence on the council of nursing, which institutionalized the profession with a registry of nurses, and which also regulated and disciplined the profession.

Descriptors: Nursing; History; Specialty Boards. 


\section{INTRODUÇÃO}

Os nexos de edificação de uma profissão, ratificado pelo caráter legal, disciplinador e fiscalizador dos órgãos representativos, imprimem qualidade e segurança ao fazer próprio profissional. Neste sentido, a Associação Brasileira de Enfermagem (ABEn) compõe o marco inicial da organização de entidades representativas da Enfermagem no país, como também da inserção da categoria como profissionais liberais em 1940 e o direito de estruturar sindicato para a defesa dos interesses da profissão $^{(1)}$. A ABEn e suas seções estaduais formaram uma rede articulada para que o Conselho de Enfermagem fosse criado na década de 1970.

Em Santa Catarina, a ABEn foi decisiva para a organização do Conselho no Estado, uma vez que todo o movimento para criação do Conselho Federal de Enfermagem (Cofen) e Conselhos Regionais de Enfermagem (Serem) foi idealizado e impulsionado dentro da ABEn e suas seções. A Associação Brasileira de Enfermagem - Seção SC (ABEn-SC) a partir de sua implantação em 1962, pela Irmã Cacilda e sob o empenho das poucas enfermeiras de Florianópolis e de Santa Catarina participaram ativamente desta iniciativa junto às enfermeiras brasileiras.

Os Congressos de Enfermagem eram espaços de socialização das discussões e na Gestão de Ingrid Ibsen (Gestão 1972-1976) a efervescência do movimento em todo o Brasil estava no seu auge e a criação do Conselho Regional de Enfermagem de Santa Catarina teve o seu apogeu. A pesquisa ora apresentada fundamentou-se na sociologia das profissões defendida por Eliot Freidson ${ }^{(2)}$. Esse autor refere que à profissão compete julgar comportamentos, uma vez que é ética o suficiente para controlar comportamentos desviantes e se auto regular. O autor se refere aos Conselhos profissionais como instâncias que apresentam processos de auto-regulação e que têm importância analítica e prática no exercício profissional. Os Conselhos apresentam, portanto, caráter legal e privado.
A criação do Conselho Profissional para a Enfermagem no Brasil foi uma conquista, para a qualificação profissional, para a gestão, o ensino e a pesquisa da profissão. O Conselho sustenta a credibilidade da profissão, por meio da fiscalização e do disciplinamento de práticas qualificadas e seguras da Enfermagem para a sociedade ${ }^{(3)}$. Em que a ação reflexiva, crítica e o diálogo aberto do enfermeiro facilita repensar a responsabilidade individual e institucional das relações do mundo do trabalho, transformando assim as condições desse trabalho ${ }^{(4)}$.

Este Estudo apresenta uma visão sobre a história da constituição deste órgão representativo, que se torna decisivo ao desenvolvimento da Enfermagem no Brasil e especificamente, para a Enfermagem catarinense. Traz à tona uma história não contada, mostrando a lacuna na literatura de história da enfermagem em Santa Catarina. Frente ao conjunto de acontecimentos nacionais para implantação do Sistema Cofen/Coren este estudo sela momentos históricos no desenvolvimento da Enfermagem como profissão num recorte inicial de implantação do Conselho no Estado catarinense e objetiva analisar as circunstâncias de criação e implantação do Conselho Regional de Enfermagem em Santa Catarina-Coren/SC (Década de 1970). O conselho profissional é um articulador e interlocutor da profissão em instâncias políticas, de ciência e tecnologia e de recursos humanos. Apresenta a função de fortalecer o coletivo profissional, qualificando as ações, normatizando os procedimentos e garantindo junto aos gestores em saúde condições dignas de trabalho ${ }^{(5)}$.

As possíveis contribuições advindas desta pesquisa apresentam-se como interface da visibilidade da profissão, para neste sentido, contribuir para a Enfermagem, a área da saúde e para a sociedade, uma vez que compromete-se com uma resposta à prática; discute o valor desta entidade organizativa para o conhecimento de Enfermagem e de sua construção nas práticas assistenciais. 


\section{ABORDAGEM METODOLÓGICA}

Pesquisa qualitativa, de caráter sócio-histórico, fundamentado nos aspectos teórico filosóficos da História Nova e da sociologia das profissões de Elliot Lázaro Freidson $^{(2)}$. O recorte temporal engloba o período de criação do órgão regulamentador da profissão Enfermagem em Santa Catarina no dia 12 de Julho de $1975^{*} \mathrm{e}$ a constituição do Conselho Federal de Enfermagem (Cofen) pela Portaria no 3.059, de 5 de março de 1975 e instalado em 23 de abril de 1975. Assim sendo, este Estudo foi composto por sujeitos que aceitaram previamente participar da Pesquisa e seguiram os critérios de inclusão pré-definidos: profissionais de Enfermagem que compuseram a estrutura organizacional e administrativa do Serem/SC, em sua criação e seu desenvolvimento, no período descrito. Participaram sete profissionais inseridas no processo de criação e instalação do Serem de Santa Catarina (SC).

O método da história oral temática em integração com a análise documental foram as opções metodológicas para a coleta dos dados, que aconteceu entre dezembro de 2011 e março de 2013. Foram apresentados aos sujeitos, em respeito a Resolução 196/96 sobre pesquisa com seres humanos, o termo de consentimento livre e esclarecido e a carta de cessão de direitos, após aprovação pelo Comitê de Ética em Pesquisa com Seres Humanos da Universidade Federal de Santa Catarina (CEPSH/UFSC) sob o Parecer $\mathrm{n}=2.329$ FR474.453, de 28/11/2011. Nessa oportunidade, os participantes do estudo consentiram a identificação dos depoimentos por meio de seus nomes completos e reais. Posteriormente, ao esclarecimento e aceite foi aplicado um roteiro de entrevista semiestruturado, sob gravação digital, subsequente transcrição e retorno das narrativas aos sujeitos para validação das informações. No âmbito das fontes documentais foram utilizados os arquivos do Cofen, do Coren/SC, da ABEn e da ABEn-SC e os arquivos particulares dos sujeitos do estudo.
A análise e interpretação das narrativas seguiu a análise cruzada da história oral temática, que são as comparações da oralidade de um entrevistado com a de outro, bem como a associação a evidências das fontes documentais. O fluxo do processo analítico respeitou as três fases definidas por Bardin ${ }^{(6)}$ : pré-análise, exploração dos dados e tratamento dos resultados e foram organizados quadros que compuseram falas completas de cada sujeito da pesquisa e unidades que significavam cada retórica. A partir daí foram classificadas e ordenadas as ideias e os fatos. Na técnica de enunciação, que se utilizou de categorias temáticas, o agrupamento das codificações se fez por significação. Emergiram da análise duas categorias: O movimento para a criação do Conselho Regional de Enfermagem de Santa Catarina e as Conjunturas de criação e instalação do Conselho Regional de Enfermagem de Santa Catarina em 1975.

\section{RESULTADOS}

Os resultados a partir da compilação de unidades de significação elencam a primeira categoria que se refere à dinâmica para a criação do Conselho Regional no Estado de Santa Catarina, a ABEn como princípio de todo este movimento e a fragilidade no desconhecimento do que vem a ser um Conselho profissional e suas implicações. $\mathrm{Na}$ segunda categoria traz-se à tona o processo de criação propriamente dito e as circunstâncias deste movimento no escopo da Enfermagem de Santa Catarina.

\section{O movimento para a criação do Conselho Regional de Enfermagem de Santa Catarina}

Em meio ao ativismo da ABEn, por meio da liderança, companheirismo e responsabilidade das Enfermeiras que compuseram a entidade, a luta pela criação do Conselho Profissional no país e no Estado foi desencadeada. Alguns depoimentos revelam este momento marcante:

\footnotetext{
* O Cofen e seus Regionais foram formalmente criados com a promulgação da Lei no 5.905, de 12 de julho de 1973.
} 
A Associação Brasileira de Enfermagem vinha lutando há 30 anos para a criação do Conselho e devido uma série de problemas, também políticos. [...] havia outros profissionais dentro do grupo de Enfermagem, outras categorias que também queriam esse Conselho (Lydia Ignes Rossi Bub).

Era algo que a ABEn estava fazendo, porque a criação do Conselho foi pela ABEn. A gente tinha uma liderança forte, a ABEn era forte (Ingrid Ibsen.)

Atrás do Conselho estava a ABEn, seguramente. Nós éramos conhecidas já, por causa da ABEn, porque a gente sempre foi batalhadora nessa área, nesses movimentos sociais (Lúcia Herta Rockenbach).

As orientações éticas configuram como base no desenvolvimento de todo este processo de institucionalização e consolidação da Enfermagem no Brasil e em Santa Catarina. A credibilidade na defesa da assistência e de padrões éticos no fazer saúde postulou como argumento para o envolvimento entre as pessoas e direcionou à criação do Conselho. Fato que se traduz nos depoimentos que se seguem:

Nós tínhamos valores muito firmes a serem preservados pela Enfermagem. O ideal da profissão, postura profissional e ética era o que prevalecia. Então nós temos amizades que duraram até hoje. Sempre a gente estava alternando cargos porque nós éramos muito poucas, e as religiosas $e$ as enfermeiras trabalhavam muito unidas nesta política, que era a política da posse. Então esse espírito de grupo esse espírito de corpo era construído assim, não tinha a divisão entre leigas e religiosas, ficamos lutando pela mesma causa, institucionalizar a Enfermagem de Santa Catarina (Eloita Pereira Neves).

A gente pensava que tínhamos que ocupar os serviços, mas não. Eu achava que o Conselho viria para mudar a assistência de verbas, para exigir a presença da área que os postos de saúde tivessem enfermeiras(os), para fazer com que aquela sonhada Enfermagem pudesse se transformar em realidade, isso eu acreditava. Por isso é que eu lutei aceitei por que eu acreditava que o Conselho ia fazer isso (Ingrid Ibsen).

O movimento para criação do Conselho profissional da Enfermagem seguia o empenho e a iniciativa da ABEn. No estado do Rio Grande do Sul a Escola de Enfermagem já havia sido criada o que caracteriza o envolvimento das Enfermeiras e professoras de lá no movimento brasileiro e incentivaram as enfermeiras catarinenses. O curso desta organização revela que a categoria no Estado catarinense estava empenhada em participar desta tarefa. Se o movimento não se ampliasse, seguramente as inúmeras jornadas dos anteprojetos não culminariam na criação do órgão regulamentador da Enfermagem. A depoente Eloita Neves nos confidenciou que:

Tinham professoras na Escola de Enfermagem da URGS, que eram as professoras Vani Maria Chicá Faraon e Maria Elena da Silva Nery, elas mantinham correspondência comigo, e como elas eram líderes desse movimento lá no Rio Grande do Sul, e elas lutavam mesmo, tinham parentescos com ministros. O Rio Grande do Sul era envolvido na política mesmo nacional, então certamente ela entrou muito em contato comigo. Sei que elas estavam muito atuantes para instalar o sistema Cofen/Conselhos Regionais, e com todas as dificuldades da época, lembro de ela ter mandado algum documento para mim, mais não lembro do que se tratava no momento, que eu não sei se ficou na ABEn-Seção Santa Catarina ou no Coren/SC (Eloita Pereira Neves).

Os profissionais da Enfermagem em Santa Catarina na época, também tinham dificuldades em entender o que era um Conselho Profissional e o que implicaria realmente a sua criação para a profissão. As lideranças estavam imbuídas em organizar todo o processo no Estado. Apesar disso elas mostravam seu desconhecimento acerca do Conselho de Enfermagem a ser instaurado. 
Sei que elas (Enfermeiras ABEn-RS) estavam muito atuantes para instalar o sistema Cofen/Coren. Já falavam das dificuldades de instalar um Conselho, quando ainda era questionado se era mesmo uma profissão. Então eu acho que essa é uma luta constante, não sei se ela já acabou ou se nós ainda temos que provar que somos uma profissão (Eloita Pereira Neves).

Eu me enfronhei muito desse movimento de instalação do Conselho em Santa Catarina, mas sem entender claramente o que significava ter um Conselho Profissional, mas me envolvi, tanto que fizemos um movimento em Blumenau, porque tinha muito Técnico e Auxiliar no ambulatório das indústrias (Solange Wink).

O movimento para a criação do Conselho Profissional da Enfermagem em Santa Catarina nasceu com um dos propósitos do Conselho Federal e sucessivamente a este, na composição dos Regionais nos Estados brasileiros.

\section{Conjunturas de criação e instalação do Conselho Regional de Santa Catarina em 1975}

Na composição dos Conselhos regionais a direção do da representatividade de Santa Catarina recaiu sobre Lydia Ignes Rossi - Conselheira Suplente da primeira Diretoria do Conselho Federal de Enfermagem. Alguns relatos reiteram esta ideia.

A Lydia Ignês Rossi, foi indicada para o Cofen, na lista tríplice, e lembro que ela foi suplente e certamente, isso fez com que ela participasse da Comissão que implantava o Serem em Santa Catarina (Eloita Pereira Neves).

Quando saiu oficialmente a criação do Cofen, a Ingrid era presidente da ABEn, então a Ingrid trouxe de um Congresso a incumbência de organizar por aqui, para indicar as representantes daqui. Sei que foi indicado a Lydia como suplente pelo Cofen.(Nelcy Terezinha Coutinho Mendes)

A rede social ampliada pelos membros da $A B E n$ possibilitou que o Secretário de Saúde Dr. Manuel
Henrique Prisco Paraíso disponibilizasse espaço físico para o desenvolvimento da comissão para organização da eleição do Conselho Regional, a qual intitulada dos trabalhos da Junta Especial, como segue referendado.

O diretor do Departamento de Saúde Pública, Doutor Osvaldo de Oliveira arrumou uma salinha pequena, sala mais ou menos desocupada, e íamos lá nos reunir. Quem que ia votar? Não estavam inscritos. Não tinha, não tinha Conselho para inscrever. A inscrição só poderia ser feita depois que tivesse um Conselho Estadual (Lydia Ignes Rossi Bub).

Aí começou o trabalho de instalação, o Estado tinha que comprovar determinadas circunstâncias de número de pessoas, de condições de funcionamento. E Santa Catarina era um dos que tinha poucas condições e aí foi designada pelo Cofen, uma comissão. Lembro que a Ingrid, se não era presidente era o elemento mais ativo, $e$ a Ingrid era uma pessoa de vontade férrea, resolveu que nós íamos ter o Serem (Rosita Alves da Silva Morgado).

Houve um grande empenho das(os) Enfermeiras(os) e Auxiliares de Enfermagem e as condições da ABEn-SC eram reduzidas, em decorrência da pequena massa de associados. O chamamento dos profissionais em Santa Catarina se fez de maneira diversificada. Ele se disseminava no espaço público e privado em todo o Estado. Este fenômeno pode ser observado nas narrativas abaixo.

Então começamos a fazer propaganda, a convidar $e$ solicitar, para que enfermeiras(os) e auxiliares viessem se inscrever, via rádio, boca a boca. Ou às vezes por exemplo, as(os) enfermeiras(os) que faziam parte de associação em todo o Estado, eles procuraram, aonde no seu município, vizinho, sabiam que tinha uma(um) enfermeira(o), então convidavam para que viesse fazer o seu registro (Lydia Ignes Rossi Bub).

Através da ABEn a gente começou a fazer esse tipo de coisa. Palestras em rádio, nas escolas, para motivar 
estudantes para a Enfermagem e na rádio até para falar como era uma Enfermagem organizada (Nelcy Terezinha Coutinho Mendes).

A partir do cadastramento dos profissionais e a homologação da chapa pelo Coren,o pleito eleitoral foi realizado com o envio das cédulas aos profissionais cadastrados e votação in loco. As lideranças, como explicitado nas falas que seguem, definiram a realização da posse em evento específico da ABEn-SC. De modo que foi garantida a participação de um maior número de profissionais no ato de instalação do Conselho. Alguns relatos nos ajudam a conhecer melhor este momento importante.

Resolvemos que faríamos a posse do Conselho numa reunião após encerrada a IV Jornada de Enfermagem, eu como representante do Conselho Federal, abri a sessão para a posse, e foi dado posse para os conselheiros (Lydia Ignes Rossi Bub),

Foi em Joinville que nós aproveitamos a jornada pra fazer a posse. A gente aproveitou toda a organização que tínhamos (Ingrid Ibsen).

O nascedouro do Conselho Regional de Enfermagem de Santa Catarina foi norteado na crença do novo, na consolidação de uma Enfermagem de excelência, centrada nos padrões definidos pela qualidade da assistência, autonomia do cuidar, responsabilidade pelo outro e compromisso com a legalidade e ética.

\section{DISCUSSÃO}

Os trâmites para o assentamento de um órgão regulamentador do fazer profissional da Enfermagem seguiram de 1944 a 1973 por iniciativa da ABEn. Os motivos de organização do Conselho seguiam a crise no país das políticas de saúde e públicas, que não davam conta de restaurar ou prevenir os agravos de saúde da população. Além disso, estes tramites se inscrevem no contexto político e econômico de inclusões e exclusões de normas trabalhistas e sindicais no país. O congraçamento, por meio da $A B E n$, em torno da organização de um órgão representativo e regulamentador dos interesses da profissão, estabeleceu-se com vistas ao controle profissional e ao fortalecimento da categoria.

Entre o final da década de 1960 e início da década de 1970, havia no estado catarinense número bastante reduzido de Enfermeiras. Na época elas eram associadas à $A B E n$ Rio Grande do Sul (ABEn-RS). Elas sentiam um determinado isolamento tanto pelas condições geográficas, como pelas diferenças no contexto cultural, de comunicação. Além disso identificavam que os problemas referentes à saúde e à Enfermagem propriamente dita, do RS diferiam daqueles vivenciados pela Associação do Estado vizinho ${ }^{(7)}$. Santa Catarina, por intervenção e empenho da Enfermeira Irmã Cacilda (Otillie Hammes) e de um grupo de Enfermeiras conseguiu organizar uma seção naquela organização gaúcha em 13 de março de 1962. Isso foi possível graças a participação de onze profissionais que residiam no Estado. Neste ano, segundo Neves ${ }^{(8)}$, o Estado de Santa Catarina estava constituído por 26 Enfermeiras: 18 eram religiosas e oito leigas. Destas últimas quatro encontravam-se fora de atividade.

o grupo apresentava ideais fortes que acompanhavam a crença e o idealismo dos membros da ABEn nacional e dos primórdios da Enfermagem. O espírito de corpo e o compromisso profissional aliados à responsabilidade com a consolidação da profissão e, principalmente, com a saúde da população, fez deste seleto grupo de pessoas, profissionais em prol da Enfermagem. O que Freidson ${ }^{(2)}$ menciona de "sentido especial de responsabilidade", onde o autor relaciona a prática profissional íntegra e suas consequências na clientela, no caso os usuários dos serviços de saúde.

$\mathrm{O}$ discurso das (os) respondentes retrata que a $A B E n$ era o centro das decisões e mostrava-se direcionadora dos atos legais, profissionais, científicos e culturais da enfermagem brasileira. Apesar de todos os problemas sociais e políticos e toda a retração do Estado, a 
enfermagem apresentava uma autonomia profissional considerável em relação à medicina, apesar de ter estado sob a supervisão desta como órgão de fiscalização, até o início da década de $1970^{(9-10)}$. Outro fator importante para a atuação do grupo profissional, a partir da Associação é que, segundo entendimento da sociologia das profissões, é no âmbito da esfera profissional que a sociedade exerce a coesão(11). E nesta perspectiva, o movimento do nascedouro do Conselho em Santa Catarina, liderado pelas enfermeiras no estado, retrata a coesão e a força necessárias a concretização desse feito. A atuação das pioneiras reflete a atitude, a ética e o comportamento a ser instituído à atividade no trabalho, que corresponde a realidade de ser profissional ${ }^{(2)}$.

A ABEn, em 5 de maio de 1973, enviou correspondência à Eloita Pereira Neves, contendo dois documentos a serem trabalhados junto aos políticos catarinenses, em favor da criação de um Conselho Profissional para a Enfermagem. O primeiro impresso tratava-se da cópia do Projeto de criação do Conselho em tramitação no Senado. O segundo era o Projeto já com alterações propostas pela ABEn Nacional. A prerrogativa do envio desta documentação atendia aos interesses da ABEn em mobilizar os profissionais em Santa Catarina para justificar e reivindicar apoio junto aos Deputados Federais, Senadores e Ministro do Trabalho Leitão de Abreu pela aprovação do Projeto com as alterações indicadas $^{(12)}$.

Nas discussões primeiras para a criação de um conselho profissional não estavam claras as finalidades deste órgão para a grande maioria dos membros da enfermagem. Havia uma dissonância no que viria a ser um órgão representativo da enfermagem no âmbito de direitos e deveres do ensino e do exercício profissional. A ABEn Nacional solicitou ao Professor Cesarino Júnior, advogado renomado nas questões trabalhistas no país, esclarecimentos acerca das competências e diferenças entre um Conselho e um Sindicato. Este solicitou ao grupo de enfermeiras envolvidas na luta pela criação da entidade representativa, após orientação, para pensar e optar pelo órgão que melhor atendesse os interesses do pessoal da Enfermagem. O que resultou na elaboração de Projetos de Lei criando o Conselho de Enfermagem ${ }^{(13)}$.

A criação do conselho demandaria discussões maiores que diziam respeito ao Sindicato das Parteiras de São Paulo, União Nacional dos Auxiliares de Enfermagem e à Conferência dos Religiosos do Brasil. Decorria uma dissonância entre as propostas das Enfermeiras e as das demais categorias que exerciam atividades da enfermagem. O Governo Federal e o Ministério do Trabalho, sob a Portaria Cofen n 01 , de 04 de agosto de 1975, posicionaram-se pela criação de um Conselho Profissional único, que abrangesse todas as categorias da enfermagem ${ }^{(14)}$.

A efervescência para a criação de um Conselho correspondia no âmbito das relações, a cumplicidade e a credibilidade nos agentes das mudanças políticas no interior da profissão. Desta feita, o conhecimento real indicativo da efetividade da ordem profissional aconteceria paulatinamente. $O$ essencial no momento era a união de corpo em defesa e em decorrência das transformações sociais que exigiam a consolidação da enfermagem. As pessoas envolvidas neste movimento viriam se preocupar com o entendimento da dinâmica e finalidades de um Conselho Profissional um pouco mais tarde o que, possivelmente, indicaria a fragilidade na compreensão e mesmo atuação do desenvolvimento do Conselho no Estado ainda hoje. Tanto que, o universo da enfermagem era questionado se era ou não uma profissão. E esta reflexão abrangia seus membros e a luta pela edificação do conselho. Esta questão ocorria pois a relação com o Estado, possivelmente, viria estabelecer a formalidade necessária ao controle próprio da ocupação sobre a sua atividade, sobre o seu trabalho ${ }^{(2)}$.

O movimento de criação do Conselho Profissional da Enfermagem em nível nacional e, consequentemente, em Santa Catarina, dentro de uma análise sociológica das profissões, veio para exercer o controle e defesa do mercado de trabalho. Nisto haja posta, a prioridade na execução de um trabalho ético, seguro e competente à 
sociedade. Em um mercado de trabalho controlado, uma ocupação somente se estabelece se seus membros profissionais forem credenciados e qualificados ${ }^{(15)}$.

A busca pelo reconhecimento oficial, do Estado e da sociedade é uma necessidade do grupo profissional, para definir sua específica área de trabalho e os limites de autoridade ao exercício da profissão. Assim, as Associações, Conselhos, Ordens e ou Colégios Profissionais trabalham para proporcionar autonomia, zelando por atitudes e compromisso ético e moral no exercício da profissão. Deste modo, elas buscam garantir reservas de mercado de trabalho ${ }^{(16)}$. Para tanto negociam a divisão do trabalho, estruturam o ensino profissional e desta maneira credenciam a ocupação em profissão.

Em meio a reviravoltas, esperas, trabalho e retrabalho, concordâncias e discordâncias, decorridas num espaço-tempo de 28 anos, a Lei de criação do Conselho Federal e Regionais de Enfermagem n ${ }^{\circ} 5.905$, de 12 de julho de 1973 foi sancionada pelo Presidente Emílio Garrastazu Médici. Outra demanda, no entanto se fazia importante: o envio da lista tríplice, com a indicação de nove nomes que comporiam os efetivos e os suplentes aos cargos do Conselho Federal, para o Ministério do Trabalho e Previdência Social. A presidente da Associação, Glete de Alcântara, encaminhou uma relação de vinte e sete nomes para os cargos efetivos e igual relação para os suplentes e insistiu para que fosse agilizada junto ao Ministério, a designação dos membros Conselheiros. Este fato foi selado com a publicação, pelo Ministro do Trabalho Arnaldo Pietro, da Portaria Ministerial $n^{\circ} 3.059$, de 5 de março de $1975^{(13)}$.

A demanda então era instalar os Regionais no território nacional, realizar o chamamento ou recrutamento dos profissionais da Enfermagem e inscrevê-los, para que efetivamente houvesse a organização do Conselho. Na conjuntura de criação havia ainda, a importante tarefa de elaboração do Código de Ética dos profissionais da Enfermagem, bem como normatizar a autarquia. Neste ponto, os profissionais de enfermagem do Brasil estariam iniciando a necessária avaliação do conhecimento e da ética profissional, por meio do exame das formas de regulação do trabalho, canalizadas ao bem e ao interesse público ${ }^{(2)}$. Toda esta orquestração foi indispensável para que a representação oficial da profissão, em negociação com o Estado para defender e expandir as vantagens jurídicas ou quem sabe a superioridade da profissão ${ }^{(2)}$. Esta organização foi essencial como órgão representativo da classe, para delinear as relações de trabalho no interior da profissão, entre as profissões da saúde e entre a profissão e a sociedade.

O próximo passo era ter profissionais inscritos oficialmente para acontecer o ato do voto. Com esta finalidade foram criadas "Juntas Especiais" - comissões em cada Estado para realizarem o cadastramento dos profissionais e aí sim, posteriormente efetuar as eleições. A documentação comprobatória do recolhimento com os documentos de inscrição corresponderiam à condição para o voto. A "Junta Especial" fornecia um protocolo, que era semelhante a um título eleitoral ${ }^{(15)}$. A citada comissão para instalação da seção regional catarinense foi designada pela Portaria Coren n001/1975. Por indicação da ABEn-SC ela foi composta pelas enfermeiras Ingrid Ibsen (Presidente) e Lúcia Herta Rockembach (Assessora Administrativa). Por meio da União Nacional dos Auxiliares de Enfermagem (UNAE) foi designada Maria Alba Monguilhott da Luz (Membro) ${ }^{(16-17)}$.

O grupo profissional em Santa Catarina ${ }^{(8)}$ seguia a "mobilidade coletiva" descrita por Larson, já que o interesse abrangia o alcance de posições econômicas e de prestígio social. Era sim, um momento em prol da visibilidade e fortalecimento da Enfermagem no Brasil, de espaços conquistados e respeitados de trabalho e ação profissional. Outrossim, era uma questão de "proteção do mercado" ou "abrigo de mercado"(2). Assim a profissão conquista o controle do acesso profissional e garante a obrigação das credenciais ocupacionais e institucionais para o exercício da atividade.

Após a realização de toda a campanha de cadastramento dos profissionais da Enfermagem 
catarinense o empenho estava em cumprir o prazo determinado para concretização do pleito eleitoral em 21 de outubro de 1975. O mandato dos eleitos estava previsto para de três anos: de 31 de outubro de 1975 a 30 de outubro de $1978^{(17-19)}$. A partir de todo o trabalho da "Junta Especial", foram enviados ao Cofen os nomes e o quantitativo de pessoal inscrito (sem registros), para compor as eleições do Conselho em Santa Catarina.

Como consequência havia a necessidade de ser organizada uma chapa que tivesse candidatos que seriam eleitos. Assim as lideranças envolvidas começaram a buscar nomes. Eles possivelmente emergiriam entre os que já circulavam na Aben-SC e nos movimentos profissionais em Santa Catarina. No Estado havia cento e cinquenta Enfermeiras(os), destes setenta e cinco eram associados da ABEn-SC ${ }^{(18)}$. Seguidas as etapas eleitorais, foi realizada homologação dos eleitos pelo Coren sob a Decisão Cofen $n^{\circ} 3 / 1975$, que dispõe sobre os resultados das eleições para as Diretorias dos Regionais. O dia estimado pelo Cofen para a efetivação do pleito diferiu do realizado pelo Conselho em Santa Catarina. Isto se deu em decorrência de solicitação do grupo de Santa Catarina ao Cofen, para realização da posse, em Joinville, no último dia da IV Jornada Catarinense de Enfermagem organizada pela ABEn-SC.

Assim, pretendia-se dar visibilidade à criação do Conselho em Santa Catarina. Diante disto, a Enfermeira Lydia Ignes Rossi, representante e membro do Cofen, empossou a Diretoria do Conselho Regional de Enfermagem de Santa Catarina, em 22 de outubro de 1975, no Joinville Tênis Clube, na cidade de Joinville, em evento de gala, que congregou os profissionais no Estado.

Com o encerramento da IV Jornada Catarinense de Enfermagem houve a primeira reunião ordinária do Serem/SC onde foram iniciados os trabalhos de eleição e posse dos membros da Diretoria do Regional. Neste ato foram eleitos para Presidente a Enfermeira Rosita Saupe (assina atualmente Rosita Alves da Silva Morgado), Secretária a Enfermeira Ottilie Hammes (Irmã Cacilda), Tesoureira a Auxiliar de Enfermagem Helena Xavier e a
Delegado-eleitor Rosita Saupe ${ }^{(20)}$. Nesta oportunidade, deu-se a concretização de um ideal profissional. Os órgãos de representação profissional passaram a atuar como dispositivo regulador entre profissionais e clientes e, ainda, nas relações inter-profissionais, garantindo o conhecimento jurídico para a criação de direitos e deveres no âmbito do fazer profissional ${ }^{(21)}$.

O movimento de criação e implantação do regional catarinense concedeu à Enfermagem o elo entre a sociedade e o Estado, sua pertinência, sua legalidade e seu valor.

\section{CONSIDERAÇÕES FINAIS}

A Associação Brasileira de Enfermagem - Seção Santa Catarina empreendeu por meio das pessoas que a integravam esforço, espírito de luta e busca por visibilidade e reconhecimento da Enfermagem como profissão do cuidado, do ensino e da gestão em saúde.

O passado contado, do nascedouro do Conselho em Santa Catarina, revela possíveis origens de fragilidades em sua prática observadas na atualidade. Os equívocos de finalidade de um Conselho vigoram como fraqueza, uma vez que os profissionais à época contavam com os limites geográficos, as condições financeiras e a abrangência do entendimento sobre o que significaria a criação de um Conselho e os fins trabalhistas desta ação. E afinal, perduram ainda hoje, o que aponta para oportunidade de novas pesquisas que façam emergir os porquês ou justificativas da fragilidade de crença na força e qualidade que o Conselho Profissional institui à profissão e a credibilidade ao profissionalismo de seus membros.

A concretização de criação e implantação do Regional catarinense concede à Enfermagem o elo entre a sociedade e o Estado, sua pertinência, sua legalidade, seu valor.

Da análise, por meio da perspectiva apresentada, o período experienciado do movimento pela criação de um Conselho Profissional para a Enfermagem, se inscreve a própria história política e econômica do país. O amadurecimento da categoria, novas leis do trabalho 
confluindo do sistema de governo brasileiro e as dificuldades em definições de políticas públicas e sociais garantiram em um determinado momento a criação do Conselho Federal e Regionais de Enfermagem.

Deste modo, a compreensão dos nexos de influência

do Conselho Profissional no desenvolvimento da

Enfermagem no Estado catarinense perpassa por todo o compromisso e responsabilidade da ABEn. Os limites e as possibilidades dessas influências vêm da organização ética, legal, política, cultural e científica da Associação de Enfermagem. Nexos esses, que confluíram para cada particularidade de estruturação do Conselho Profissional da Enfermagem no Estado.

\section{REFERÊNCIAS}

1. Bock LF, VaghettiHH, Bellaguarda MLR, Padilha MI, Borenstein MS. A organização da enfermagem e da saúde no contexto da idade contemporânea (1930-1960). In: Padilha MI, Borenstein MS, Santos I, editores.Enfermagem história de uma profissão. São Caetano do Sul: Difusão Editora; 2011. p. 253-94.

2. Freidson E. Profissão médica: um estudo de sociologia do conhecimento aplicado. São Paulo: UNESP;2009.

3. Bellaguarda MLR, Padilha MI, Pereira Neto AF, Pires D, Peres MAA. Reflexão sobre a legitimidade da autonomia da enfermagem no campo das profissões de saúde à luz das ideias de Eliot Freidson. Esc. Anna Nery 2013;17(2):369-74.

4. Freitas GF, Oguisso T, Fernandes MFP. Fundamentos éticos e morais na prática de enfermagem. Enfermagem em Foco 2010; 1(3):104-108 5. Silva MN, Albuquerque GL, Barreto IS.Organização políticoprofissional da enfermagem: Sistema Cofen/Conselhos Regionais na luta pelos ideais da enfermagem brasileira. Enfermagem em Foco 2011; 2(1): 46-5

6. Bardin L. Análise de conteúdo. Lisboa: Edições 70; 2010.

7. Zago AT, Martins CR, Borenstein MS. Projeto: a trajetória da Associação Brasileira de Enfermagem - Seção de Santa Catarina: atos, fatos e imagens(1962-2009). In: Zago AT, organizadoras, Série Memória ABEn:contribuições da ABEn para a enfermagem catarinense. v. 1. Florianópolis: Associação Brasileira de Enfermagem- Seção Santa Catarina; 2010. p. 09-20.

8. Neves EP. A Associação Brasileira de Enfermagem - Seção Santa Catarina e a repercussão na criação do Curso de Graduação em Enfermagem na UFSC. In: Zago AT, organizadora. Série Memória ABEn: contribuições da ABEn para a enfermagem catarinense. v. 1.

Florianópolis: Associação Brasileira de Enfermagem-Seção Santa Catarina; 2010. p.21-46.

9. Almeida FO. Reforma sanitária e política: as relações entre o processo de profissionalização dos médicos de São Paulo e políticas de saúde de governo estadual de Adhemar de Barros (1947-1951).

[dissertação].São Carlos: Universidade Federal de São Carlos, Programa de Pós Graduação em Sociologia; 2010.

10. Ribeiro JMS. Autonomia profissional dos enfermeiros. Rev. Enf. Ref. 2011;serlII(5):27-36.

11. Barbosa MLO. Para onde vai a classe média: um novo profissionalismo no Brasil? Tempo Social. 1998;10(1):129-42. 12. Ministério do Trabalho (BR). Enfermagem criação e instalação de sua autarquia profissional. Relatório apresentado pelos membros designados na Portaria no 3.059, de 5 de marco de 1975 do excelentíssimo senhor Ministro do trabalho, Baixada de acordo com o disposto no artigo 21 da Lei no 5.905, de 12 de julho de 1973 . Gestão 23 de abril de 1975 a 22 de abril de 1976. Brasília: COFEN; 1976. 13. Carvalho AC. Associação Brasileira de Enfermagem, 1926-1976: documentário. 2 ed. Brasília: ABEn Nacional; 2008.

14. Bellaguarda MLR, Bub LIR, Ibsen I. A Associação Brasileira de Enfermagem-Seção Santa Catarina e a criação do Conselho Regional de
Enfermagem de Santa Catarina. In: Zago AT, organizadora. Série Memória ABEn: contribuições da ABEn para a enfermagem catarinense. v. 1. Florianópolis: Associação Brasileira de EnfermagemSeção Santa Catarina; 2010. p. 47-56.

15. Freidson E. Para uma análise comparativa das profissões: a institucionalização do discurso e dos conhecimentos formais. Revista Brasileira de Ciências Sociais. 1996;31(11):141-54.

16. Ferreira MF, Silva CFR. Reformas da gestão na saúde - desafios que se colocam aos enfermeiros. Rev. Enf. Ref. 2012;serllI(8):85-93.

17. Garcia CLM, Moreira AA. Associação Brasileira de Enfermagem e a criação do Conselho Profissional no Brasil. Rev. de Pesq.: cuidado é fundamental[Internet]. 2009 [acesso 2011 Jul;1(1):97-110. Disponível em:

http://seer.unirio.br/index.php/cuidadofundamental/article/viewArticl e.

18. Ministério do Trabalho (BR). Conselho Federal de Enfermagem.

Enfermagem: criação e instalação da sua autarquia profissional.

Relatório apresentado pelos membros designados na Portaria n. 3.059, de 5 de marco de 1975 do excelentíssimo senhor ministro do trabalho, baixada de acordo com o disposto no artigo 21 da Lei n. 5.905, de 12 de julho de 1973. 23 de abril de 1976.Brasília: Ministério do Trabalho; 1976.

19. Oliveira MIR, Ferraz NMF. ABEn na criação, implantação e desenvolvimento dos conselhos de Enfermagem. RevBrasEnferm2001;54(2): 208-12.

20. Conselho Regional de Enfermagem (SC).Ata da 1a reunião ordinária de plenário, realizada no dia 22 de outubro de 1975.Livro 1, p. 1 - 3. Florianópolis: Coren; 1975.

21. Oguisso T, Schmidt MJ, Freitas GF. Fundamentos teóricos e jurídicos da profissão de enfermagem. Enfermagem em Foco 2010; 1(1):09-13.

Recebido: 20/03/2014.

Aceito: 05/02/2015.

Publicado: 30/06/2015. 